\title{
Mechatronic CONCEPT OF HeAVy MACHINe ToOLS
}

\author{
Petr Janda
}
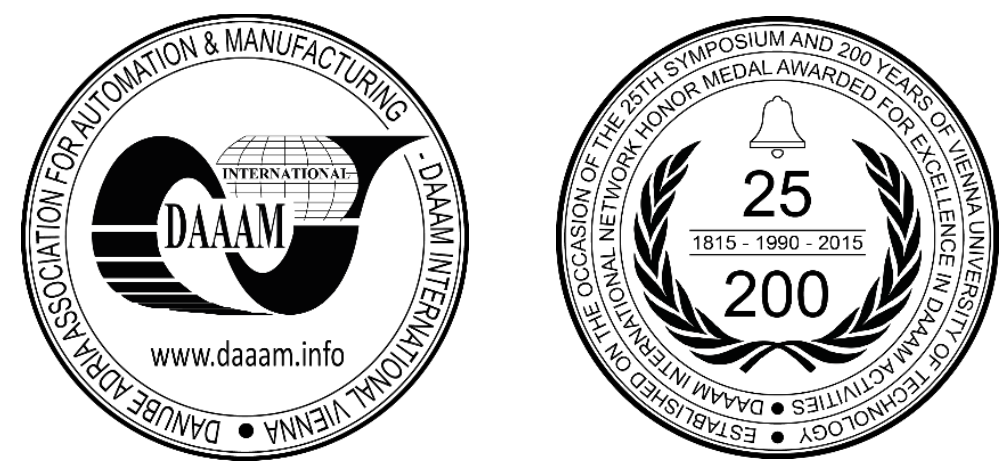

This Publication has to be referred as: Janda, P[etr] (2018). Mechatronic Concept of Heavy Machine Tools, Proceedings of the 29th DAAAM International Symposium, pp.0645-0652, B. Katalinic (Ed.), Published by DAAAM International, ISBN 978-3-902734-20-4, ISSN 1726-9679, Vienna, Austria

DOI: $10.2507 / 29$ th.daaam.proceedings.093

\begin{abstract}
Frequently discussed topic related to the modern trend of Industry 4.0 is the issue of virtual commissioning. This paper focuses on the development of a virtual model (the so-called digital twin) of a real heavy machine tool. In the field of heavy machine tools, this topic is completely new. The paper contains a general description of this issue and the short review of the works dealing with this topic. The development of the virtual model is realized in the Siemens NX environment using the Sinumerik 840D control system. The digital twin is used to test machine parameters. This work is an introductory step for the implementation of the virtual commissioning methodology in the development of heavy machine tools.
\end{abstract}

Keywords: mechatronic concept; virtual commissioning; digital twin; heavy machine tool

\section{Introduction}

Industry 4.0 is currently one of the most discussed topics in many companies and research centers and universities. Many authors also deal with this topic in their papers [1], [2], [3]. One of the most important parts of Industry 4.0 is virtualization. At University of West Bohemia, we have been dealing with numerical simulations for many years. Our focus is on optimizing the design of heavy machine tools [4]. Our goal is to improve our optimization practices using state-of-the-art trends.

This paper focuses on the development of a virtual mechatronic model of a heavy machine tool (often called digital twin). This project is in cooperation with the manufacturer of heavy machine tools (Skoda Machine Tool). Horizontal boring machines and lathes of the Skoda Machine Tool are one of the largest machines in the world. The operating time of these machines is very expensive and so there is a great effort to increase reliability. The great effort is also to reduce the time required to put the machine into operation. The implementation of the virtual commissioning in the development process has great potential in this sector.

In the field of heavy machine tools, this topic is completely new. Direct implementation of virtual commissioning in the process of developing a new machine presents the risk of extending delivery dates. For this reason, the digital twin development process has been chosen for an already produced machine. The virtual model is operated in the Siemens NX system and controlled by the Sinumerik 840 D control system. 


\section{Literature overview}

Many authors deal with the issue of mechatronic models [8], [10], [11]. If we focus only on the area of machining, this topic is no longer so common. But it is clear that digital twin is very important for the future of manufacturing [5]. An interesting application is the simulation and virtual commissioning architecture of intelligent machine tool (Gantry System) [6].

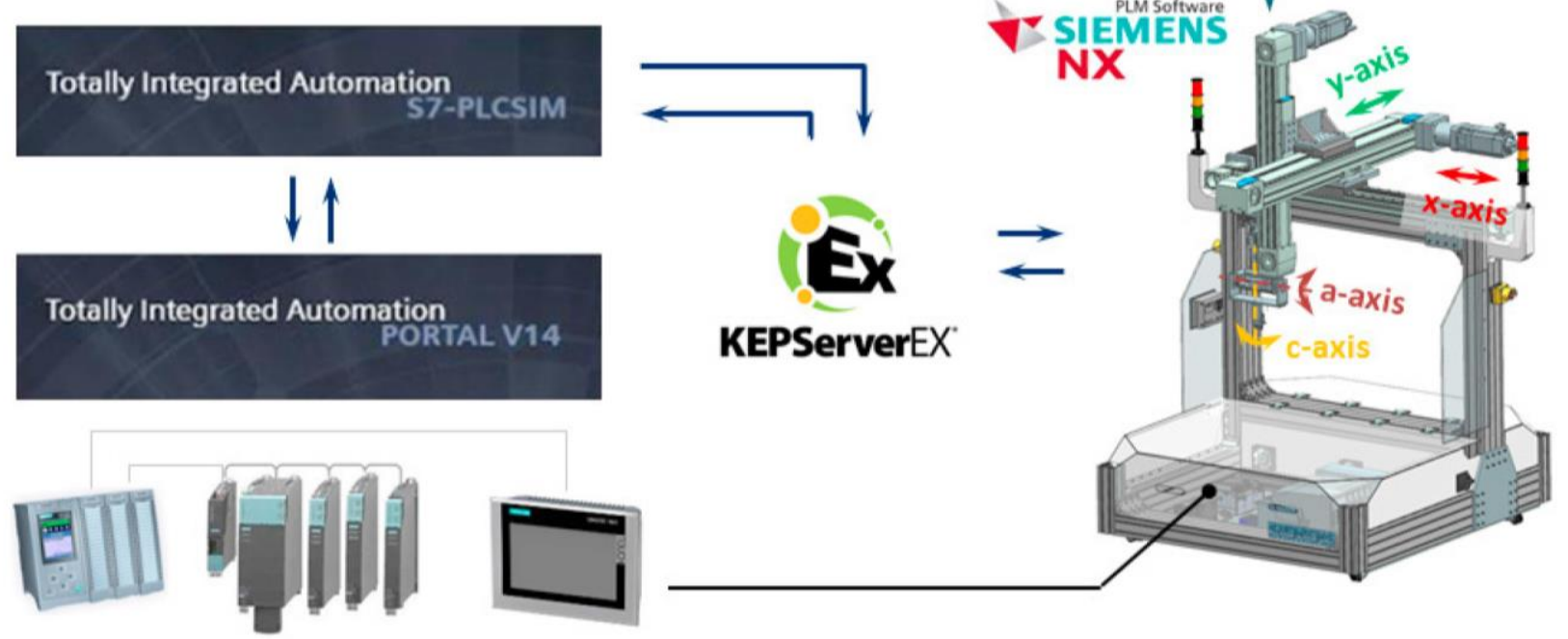

Fig. 1. The simulation and virtual commissioning architecture of intelligent machine tool (Gantry System) [6]

Next paper therefore demonstrates how the application of the virtual engineering tools support the development of a Cyber Physical Systems using an e-machine assembly station as a case study [7]. An article focusing on the twin issue for a CNC machine was published by Shandong University in China this year [9]. It is clear from the literature overview that no publication dealing with the digital twin issue of a heavy machine tool was found. This topic is quite new.

\section{Mechatronic model (Digital Twin)}

The main goal is to create a digital twin of a real machine. This issue is solved in the project on which we cooperate with the Škoda Machine Tool. The mechatronic concept of the horizontal boring machine was created. The main idea of the solution is the same control unit for both real machine

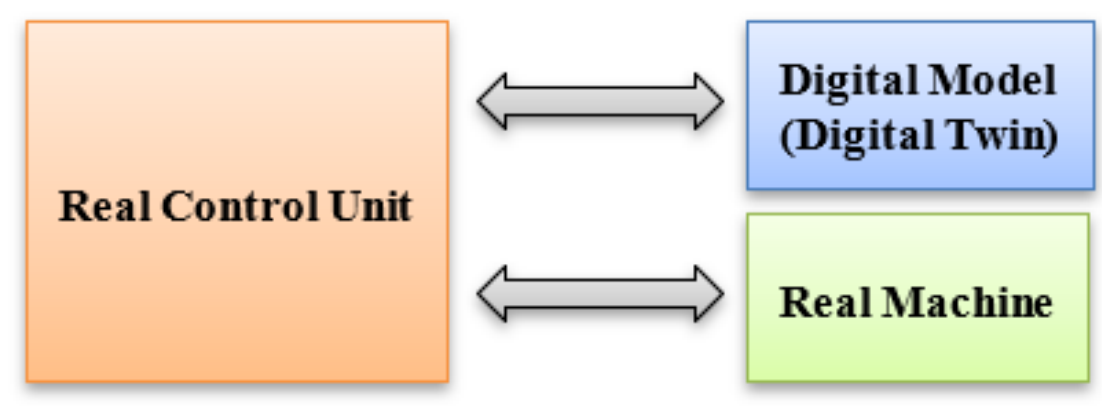

Fig. 2. Main idea of Digital Twin

This mechatronic model consists of three main parts: Virtual machine model, PLC simulation and control system. The parts are described below.

\subsection{Virtual machine model}

The virtual model is created in the Siemens NX 12 (Fig. 3). The Siemens NX system includes a dedicated module for developing virtual models called Mechatronic Concept Designer (MCD). Machine geometry is represented by 3D models with defined interconnections. Simplification of geometry is necessary for the smooth running of the simulation. If necessary, it is possible to simulate the detailed parts separately. Each virtual model must contain the mechanical, electrical and automation elements. 


\section{Mechanical definition}

- Rigid bodies which represent individual parts of the machine. Each rigid body has information about weight, centre of gravity, and moments of inertia. It is also possible to define collision bodies with specific collision material definition.

- Joints that connect rigid bodies. Commonly used joints include sliding joint, hinge joint or cylindrical joint. For each joint, it is possible to define upper and lower limits.

\section{Electrical definition}

- Position or speed control that define speed limits, maximal acceleration and maximal deceleration, limit jerk and limit force. Controllers could be driven by signals.

- Signals are divided into inputs and outputs. In this case, input signals are used to control position controllers.

- Sensors can be used to detect position, speed, acceleration etc. The sensor output is a signal.

\section{Automation definition}

- Operations represent the realization of the chosen action based on fulfilment of the conditions. For example, stopping the feed when reaching the end position.

- Signal mapping connects signals from Siemens NX with signals shared through Simit.

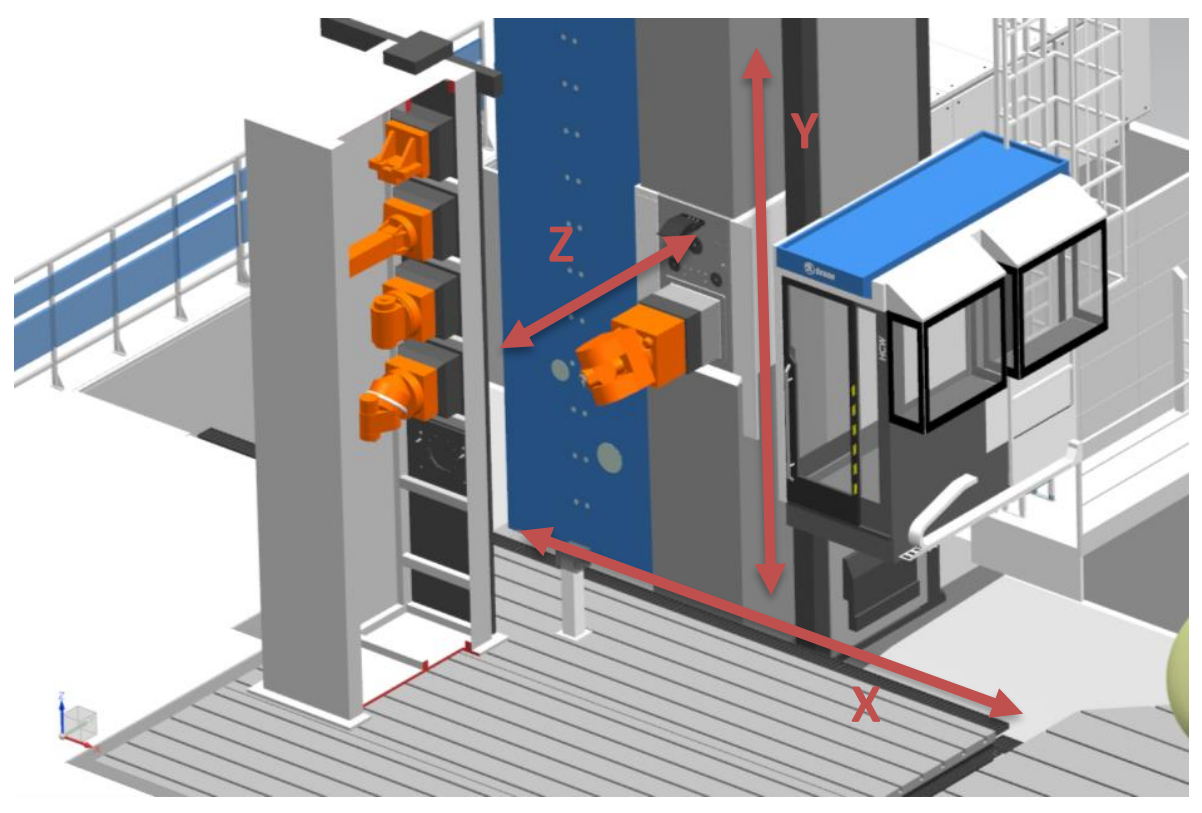

Fig. 3. Virtual machine tool in Siemens NX

\subsection{PLC Simulation}

Simit 9 software in combination with Simba-box is used for PLC simulation. In this program the signals from PROFINET and Siemens NX are connected. Fig. 4 shows an example of a function block for checking the current accessory. The signal from the sensor is returned to the control unit.
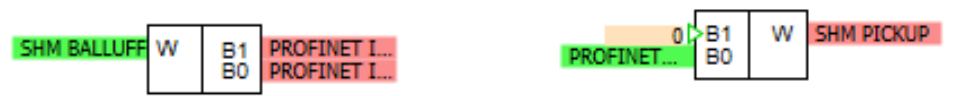

Fig. 4. Function block for checking current accessories.

The main function block for linking control signals for each axis is shown in the Fig. 5. This simit block is called ADAS and with this block, information about the position of individual axes is transmitted based on time. For the horizontal boring machine, the following axes must be transferred:

- SHM XM: Longitudinal movement of the column.

- $\quad$ SHM YM: Vertical headstock movement

- $\quad$ SHM ZM: Ram extension. 
- SHM W: Spindle extension.

- SHM V: Rotary table movement.

- SHM B: Rotation of table plate.

- SHM C: Spindle rotation.

- SHM C1: Rotation of milling head (optional).

- SHM A1: Rotation of milling head (optional).

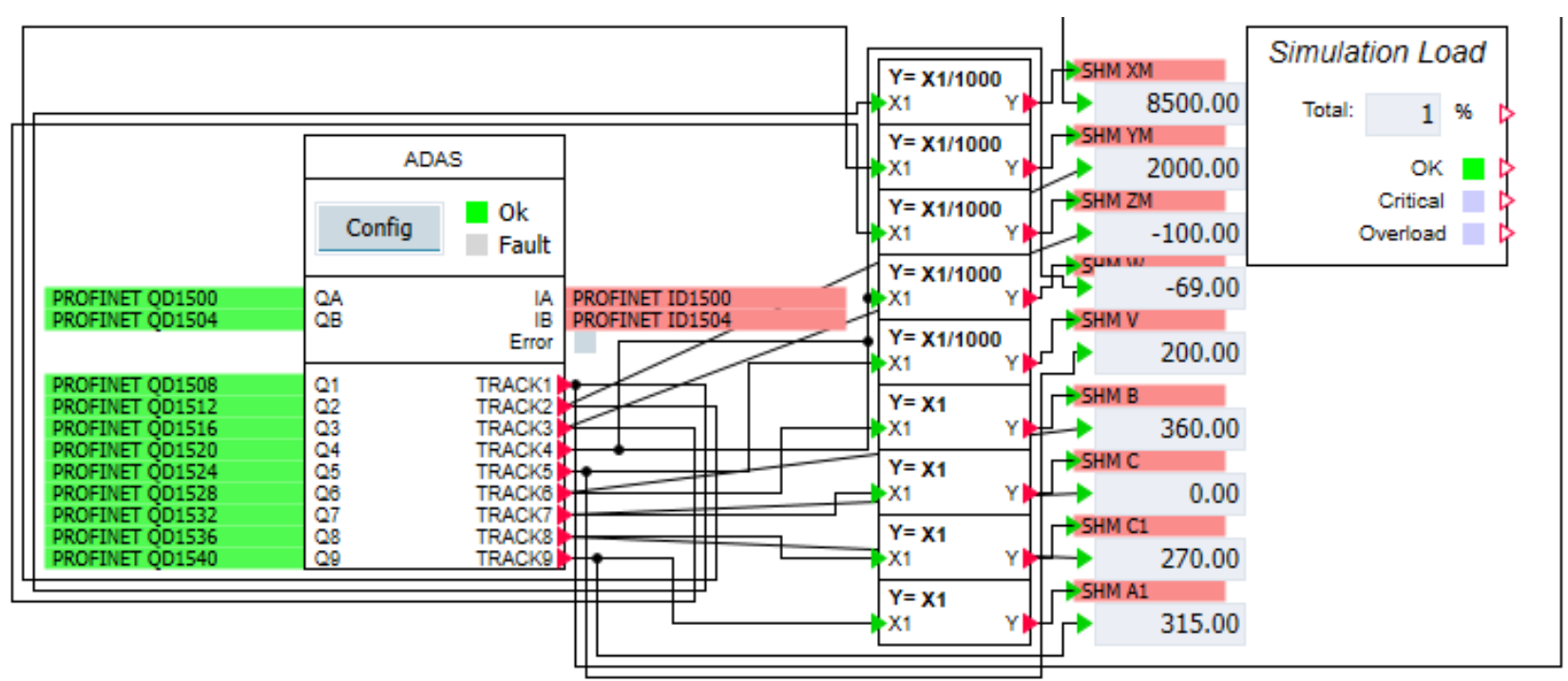

Fig. 5. ADAS function block

\subsection{Control system}

The Sinumerik 840D control system is used to control the virtual machine. A stand containing the same hardware and software as the real machine was built for simulation purposes. The test stand includes a touch screen and hardware buttons for manual control of the machine (Fig. 6).

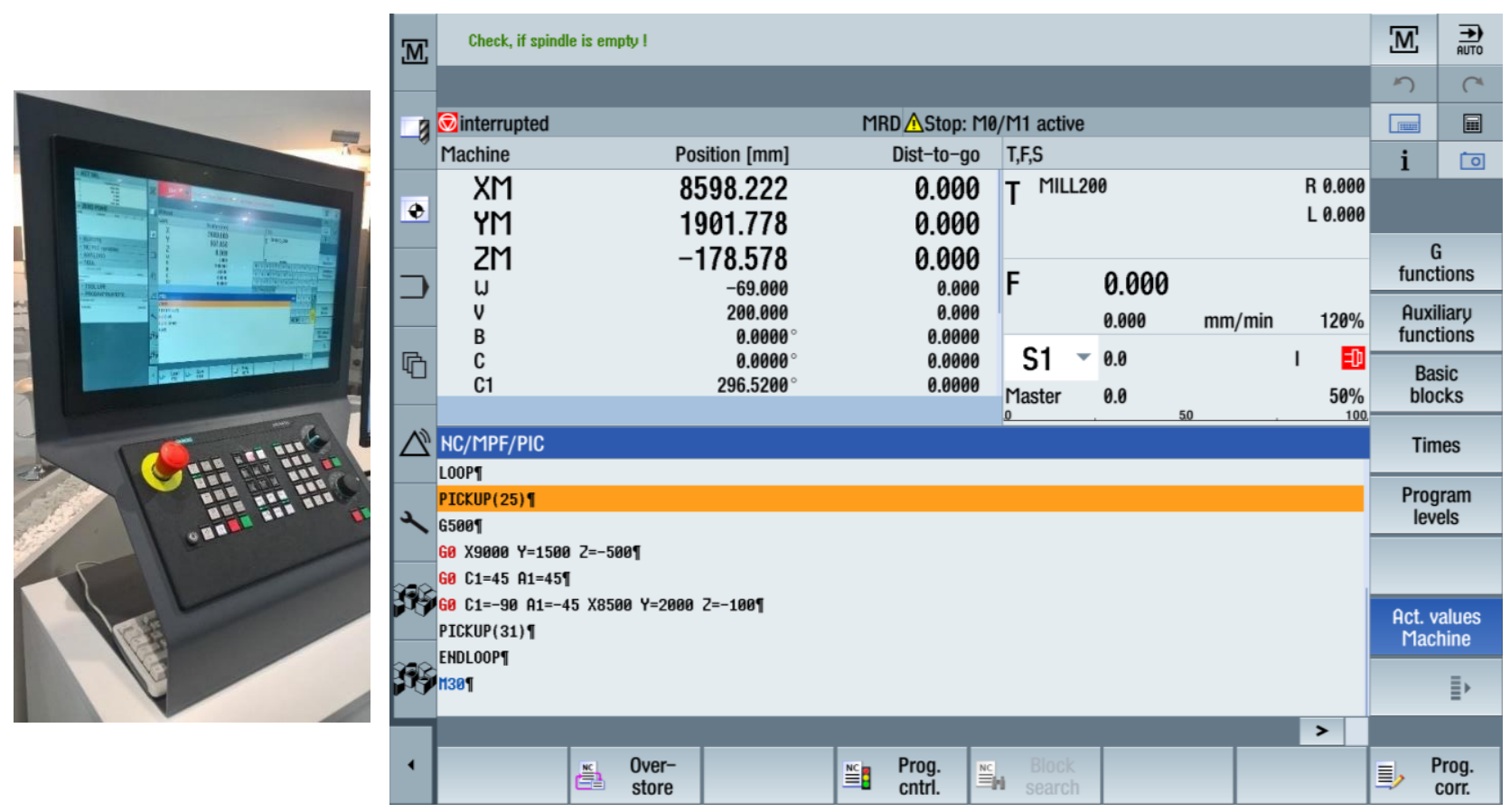

Fig. 6. Test stand with Sinumerik 840D control panel touch screen

The system contains a complete archive of the real machine. There are real operator messages, custom menus, and machine configurations. This is the same system that the real machine controls. 


\section{Results}

\subsection{Stop position analysis}

Within the mechatronic concept, the movement of the machine cabin was solved. The cabin displacement is solved by a hydraulic cylinder and controlled only by the speed. Using the mechatronic concept, the position of the cabin can be analysed when it is stopped. It is possible to optimize the end positions. On the real machine, the cabin is controlled by the hardware buttons that are not on the test stand panel. For this reason, it was necessary to create custom software buttons in the Simit environment (Fig. 7).

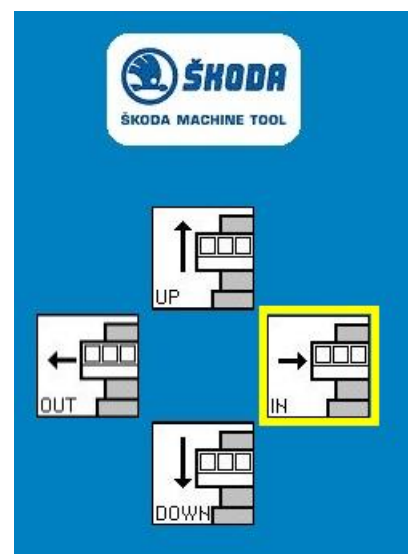

Fig. 7. Software buttons for cabin movement created in Simit.

Based on the tests, it can be said that the cabin crossings correspond to reality. However, a slight delay in response to the press of the soft keys was observed. A detailed comparison with the real machine has not been performed and will be part of further research.

\subsection{Optimization of drives}

The optimization of drives was also tested. For proper functionality, it is necessary to set the drive parameters on the virtual model side as well as on the control system side. Fig. 8 shows a parameter setting for the X axis in Siemens NX. Parameters of maximum speed, maximum acceleration and maximum jerk have been set for all axis. The set values are shown in the Table 1.

\begin{tabular}{|c|c|c|c|c|}
\hline Axis & $\begin{array}{c}\text { Speed } \\
{[\mathbf{m} / \mathbf{s}]}\end{array}$ & $\begin{array}{c}\text { Max Acceleration } \\
{\left[\mathbf{m} / \mathbf{s}^{2}\right]}\end{array}$ & $\begin{array}{c}\text { Max Deceleration } \\
{\left[\mathbf{m} / \mathbf{s}^{\mathbf{2}}\right]}\end{array}$ & $\begin{array}{c}\text { Max Jerk } \\
{\left[\mathbf{m} / \mathbf{s}^{\mathbf{3}}\right]}\end{array}$ \\
\hline $\mathrm{X}$ & 0.1667 & 0.25 & 0.25 & 0.2 \\
\hline $\mathrm{Y}$ & 0.1667 & 0.25 & 0.25 & 0.2 \\
\hline $\mathrm{Z}$ & 0.1667 & 0.25 & 0.25 & 0.2 \\
\hline $\mathrm{W}$ & 0.1667 & 0.25 & 0.25 & 0.2 \\
\hline
\end{tabular}

Table 1. Linear axis parameters

\begin{tabular}{|c|c|c|c|}
\hline \multicolumn{2}{|c|}{ 하 Position Control } & \multicolumn{2}{|r|}{$0 \times$} \\
\hline \multicolumn{2}{|l|}{ Physics Object } & & $\wedge$ \\
\hline \multicolumn{2}{|c|}{$\checkmark$ Select Object (1) } & & $\phi$ \\
\hline \multicolumn{2}{|l|}{ Constraints } & & $\wedge$ \\
\hline \multirow{2}{*}{$\begin{array}{l}\text { Destination } \\
\text { Speed }\end{array}$} & 2000 & $\mathrm{~mm} \cdot$ & $\rightarrow$ \\
\hline & 166.66 & $\mathrm{~mm} / \mathrm{s}=$ & $\because$ \\
\hline \multicolumn{4}{|c|}{$\square$ Limit Acceleration } \\
\hline \multirow{2}{*}{$\begin{array}{l}\text { Max Acceleration } \\
\text { Max Deceleration }\end{array}$} & 0.25 & $\mathrm{~m} / \mathrm{s}^{2}$. & 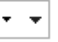 \\
\hline & 0.25 & $\mathrm{~m} / \mathrm{s}^{2}$. & $\rightarrow$ \\
\hline \multicolumn{4}{|l|}{$\square$ Limit Jerk } \\
\hline Max Jerk & 0.2 & $\mathrm{~m} / \mathrm{s}^{3}$. & $\rightarrow$ \\
\hline$\square$ Limit Force & & & \\
\hline
\end{tabular}

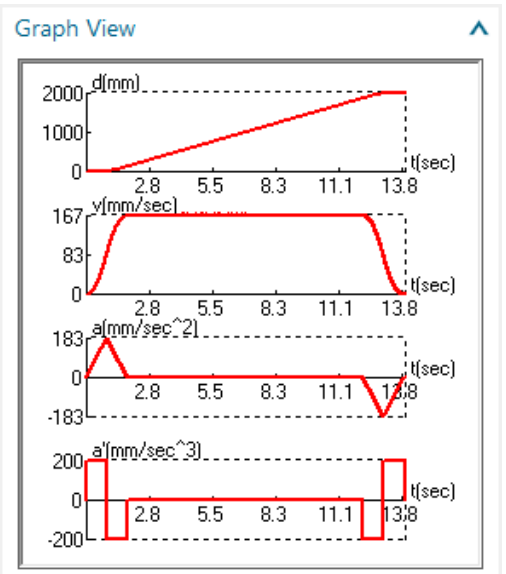

Fig. 8. Setting of drive parameters in Siemens NX 
The same parameter values were also set in the Sinumerik 840D environment as shown in Fig. 9. A setting with the jerk turned on and off was tested. If the jerk is off in Sinumerik, it is also necessary to turn off this parameter in NX. The goal was to compare the feed rate behaviour.

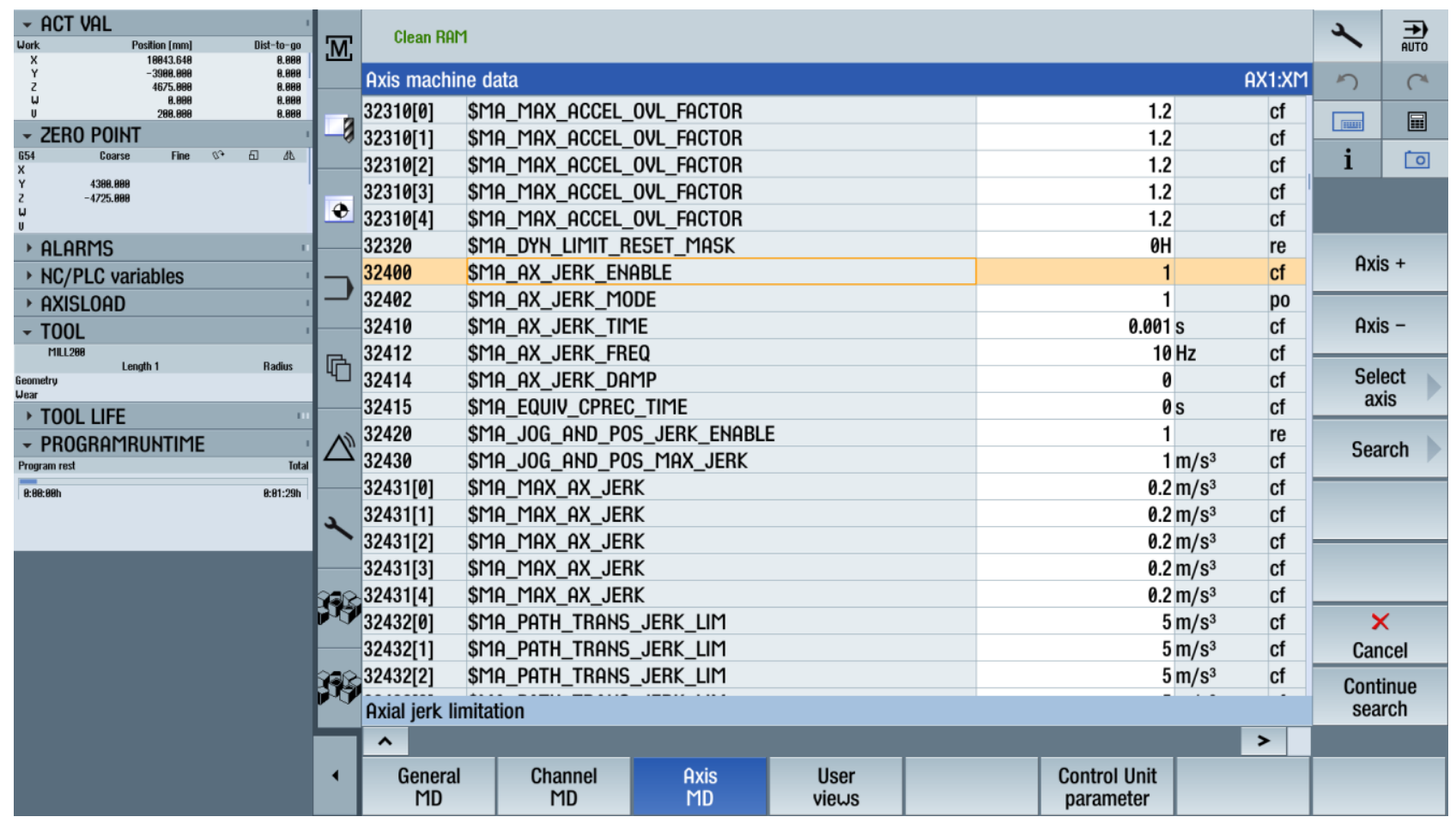

Fig. 9. Settings of axis parameters in Sinumerik

The setup test was performed on the $\mathrm{X}$ axis. When the jerk is off, there is little vibration when starting the machine. The vibration is visible in the graph of displacement and speed as a function of time (Fig. 10). This behaviour was not observed in a real machine. This phenomenon will need to be removed in the future.

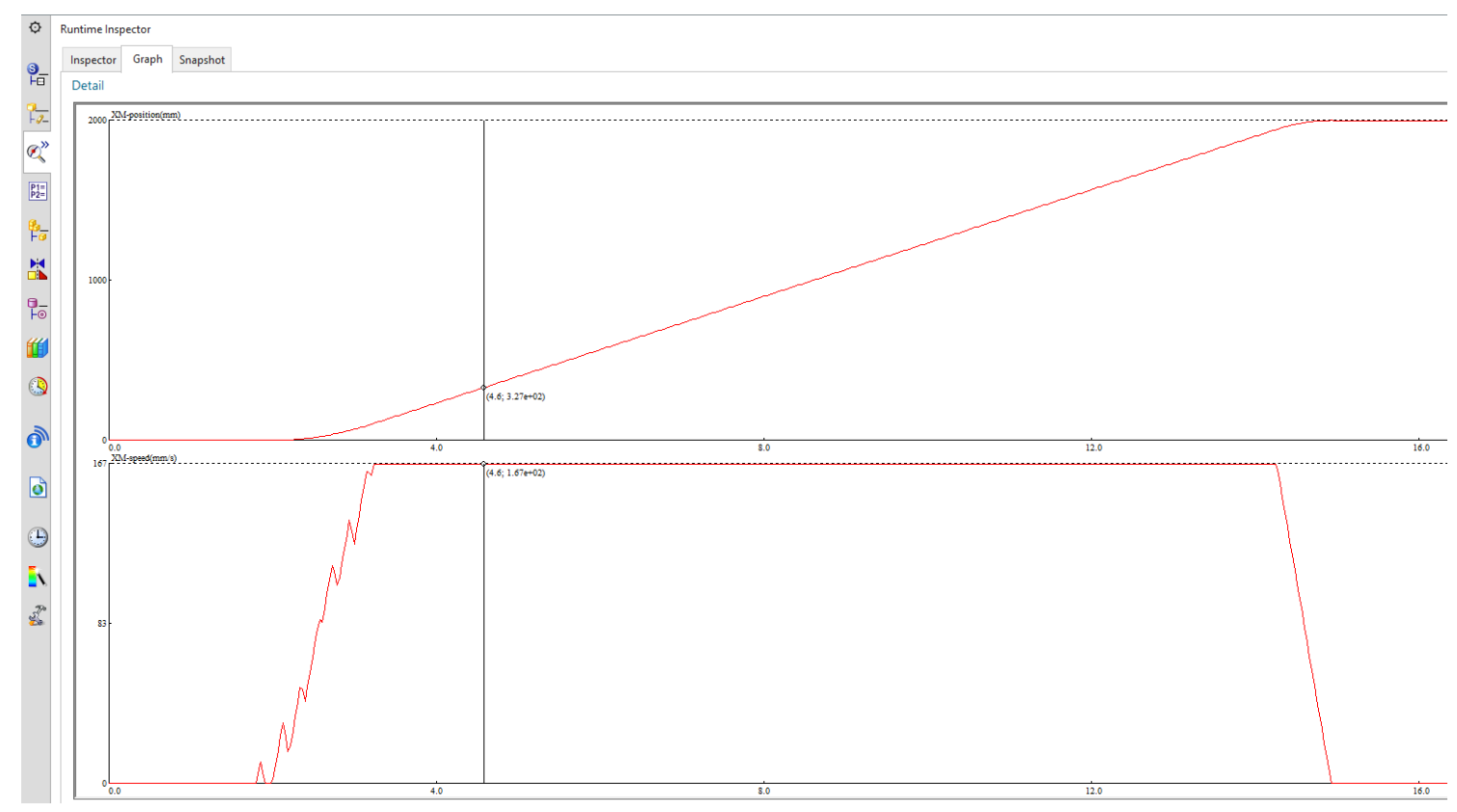

Fig. 10. Graph of displacement and speed as a function of time - Jerk OFF

If the jerk is on, there are no vibrations. There is a smooth start in the graph of displacement and speed as a function of time. This behaviour corresponds to the behaviour of the real machine (Fig. 11). The exact comparison of the movement characteristics of the virtual and real machines is subject to further investigation. 


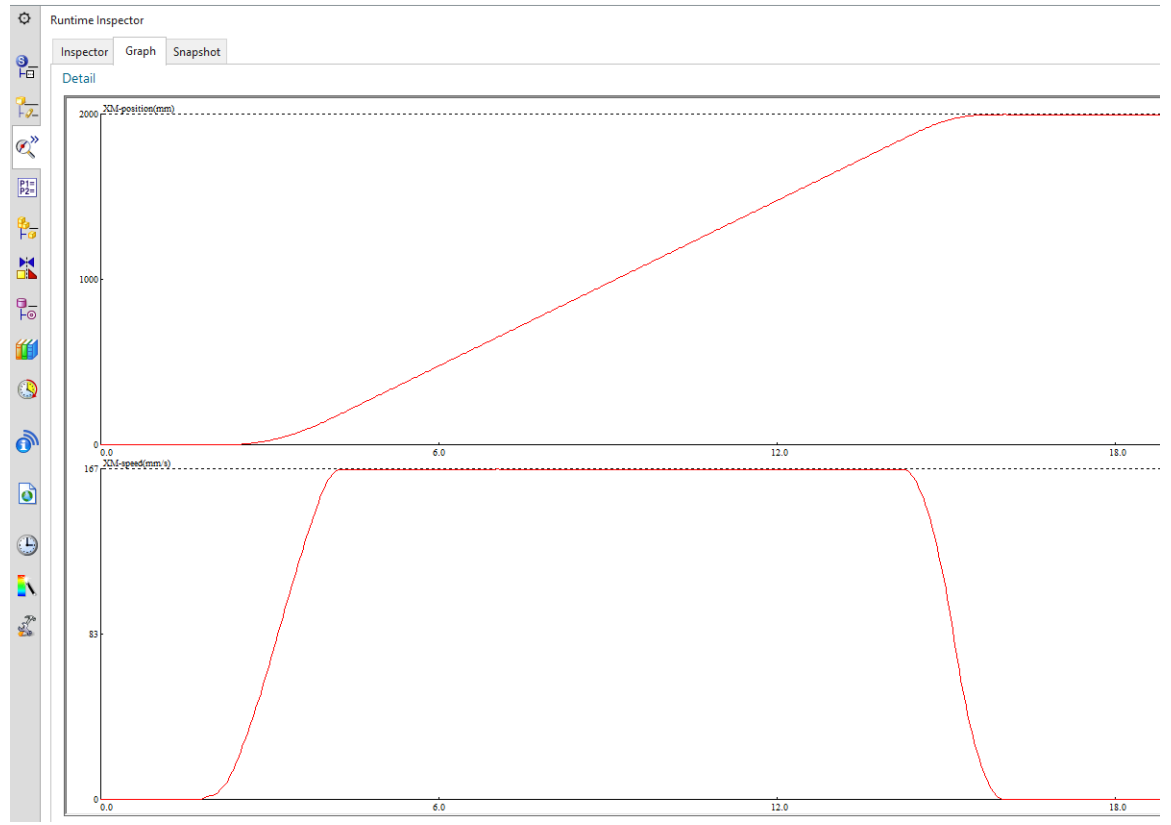

Fig. 11. Graph of displacement and speed as a function of time - Jerk ON

\subsection{Introduction of a digital twin at the fair}

The test stand representing the digital twin was exhibited at the AMB Stuttgart Messe (Fig. 12.). Thanks to this solution, one of the largest machines in the world could be introduced to visitors. Digital twin is the ideal tool for presenting new machines at minimal cost.

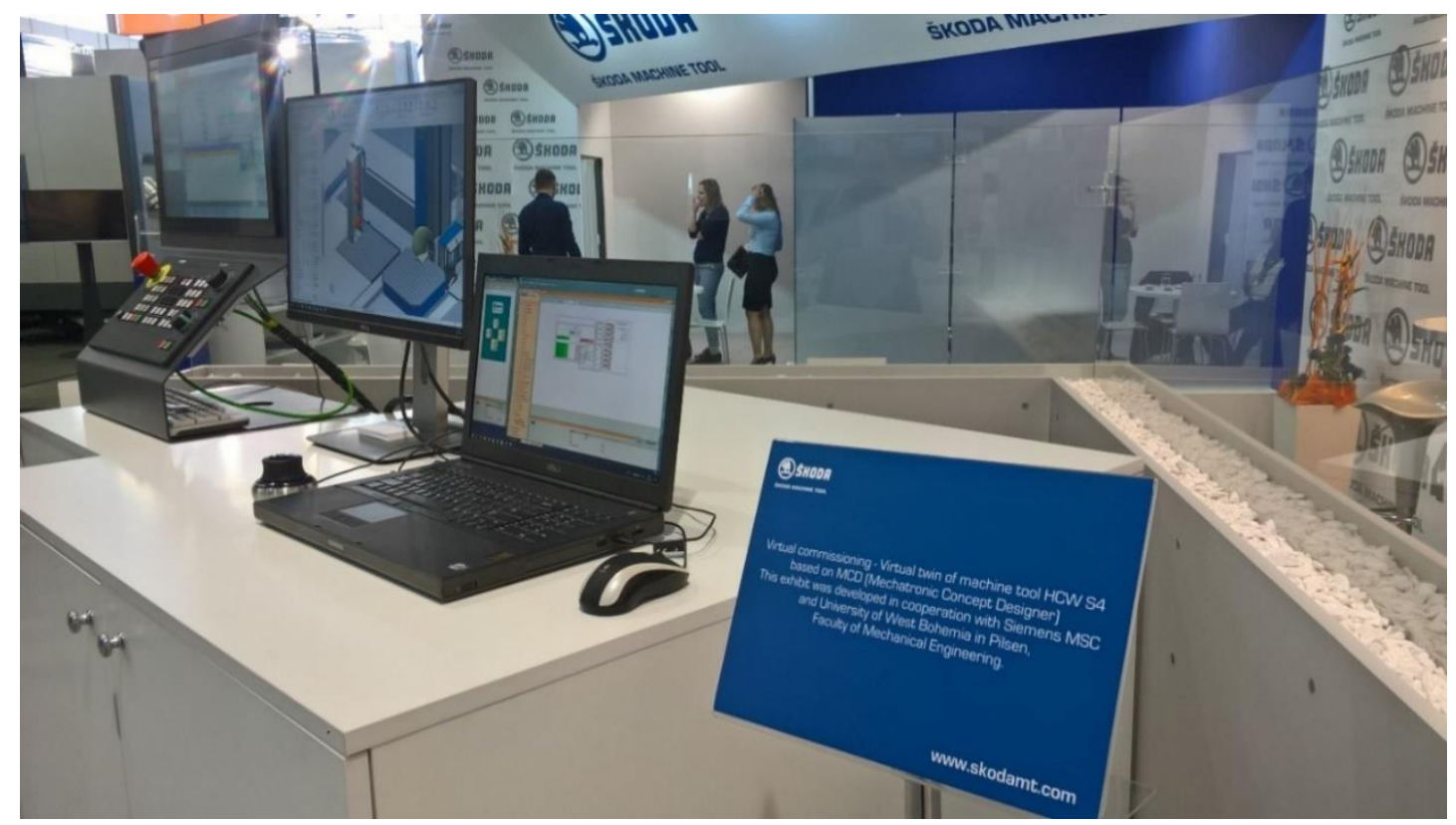

Fig. 12. Presentation of Virtual commissioning at the AMB Stuttgart Messe

\section{Conclusion}

The first step in implementing virtual commissioning has been done. The digital twin of the real heavy machine tool has been developed with the use of Siemens NX, Simit and Sinumerik 840D. The possibility of virtual commissioning the heavy machine tool was tested. There is considerable potential to save time in the commissioning and testing of the machine. The results of this work were also presented at the AMB Stuttgart Messe, where it was unique in the field of heavy machine tools.

The next step will be to deploy this concept in the development of the new machine. In the future, measurements will be made on a real machine and the results will be compared with the virtual model. Based on measurements, it is necessary to further refine the virtual model. 


\section{Acknowledgments}

The paper was supported by project FV10219 - Multipurpose turning centre for machining large and complex parts of a rotating character designed for power engineering and renewable resources.

\section{References}

[1] Liao, Y., Deschamps, F., Loures, E. D. F. R., \& Ramos, L. F. P. (2017). Past, present and future of Industry 4.0-a systematic literature review and research agenda proposal. International journal of production research, 55(12), 3609-3629.

[2] Zhong, R. Y., Xu, X., Klotz, E., \& Newman, S. T. (2017). Intelligent manufacturing in the context of industry 4.0: a review. Engineering, 3(5), 616-630.

[3] Roblek, V., Meško, M., \& Krapež, A. (2016). A complex view of industry 4.0. Sage Open, 6(2), 2158244016653987.

[4] Janda, P., \& Polak, R. (2015). Virtual prototyping and optimization of heavy machine tools. Annals of DAAAM \& Proceedings, 26(1).

[5] Rosen, R., Von Wichert, G., Lo, G., \& Bettenhausen, K. D. (2015). About the importance of autonomy and digital twins for the future of manufacturing. IFAC-PapersOnLine, 48(3), 567-572.

[6] Bank, H. S., D'souza, S., \& Rasam, A. (2018). Temporal Logic (TL)-Based Autonomy for Smart Manufacturing Systems. Procedia Manufacturing, 26, 1221-1229.

[7] Konstantinov, S., Ahmad, M., Ananthanarayan, K., \& Harrison, R. (2017). The Cyber-Physical e-machine Manufacturing System: Virtual Engineering for Complete Lifecycle Support. Procedia CIRP, 63, 119-124.

[8] Mcharek, M., Azib, T., Hammadi, M., Choley, J. Y., \& Larouci, C. (2018). Knowledge sharing for mechatronic systems design and optimization. IFAC-PapersOnLine, 51(11), 1365-1370.

[9] Luo, W., Hu, T., Zhang, C., \& Wei, Y. (2018). Digital twin for CNC machine tool: modeling and using strategy. Journal of Ambient Intelligence and Humanized Computing, 1-12.

[10] Giberti, H., Sbaglia, L., \& Silvestri, M. (2017). Mechatronic Design for an Extrusion-Based Additive Manufacturing Machine. Machines, 5(4), 29.

[11] Neugebauer, R., Ihlenfeldt, S., Frieß, U., Wabner, M., \& Rauh, S. (2012). New high-speed machine tool structure by holistic mechatronic systems design. Procedia CIRP, 1, 307-312. 